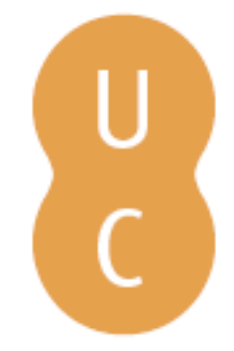

\title{
pommalina
}

\section{Um olhar Freireano sobre a construção de políticas públicas para EJA: dois exemplos recentes no Brasil}

\author{
Autor(es): $\quad$ Teles, Jorge \\ Publicado por: Imprensa da Universidade de Coimbra \\ URL \\ persistente: URI:http://hdl.handle.net/10316.2/41307 \\ DOI: $\quad$ DOI:https://doi.org/10.14195/978 $\quad$ 289 26 1326-0_18 \\ Accessed : $\quad$ 26-Apr-2023 16:22:02
}

A navegação consulta e descarregamento dos títulos inseridos nas Bibliotecas Digitais UC Digitalis, UC Pombalina e UC Impactum, pressupõem a aceitação plena e sem reservas dos Termos e Condições de Uso destas Bibliotecas Digitais, disponíveis em https://digitalis.uc.pt/pt-pt/termos.

Conforme exposto nos referidos Termos e Condições de Uso, o descarregamento de títulos de acesso restrito requer uma licença válida de autorização devendo o utilizador aceder ao(s) documento(s) a partir de um endereço de IP da instituição detentora da supramencionada licença.

Ao utilizador é apenas permitido o descarregamento para uso pessoal, pelo que o emprego do(s) título(s) descarregado(s) para outro fim, designadamente comercial, carece de autorização do respetivo autor ou editor da obra.

Na medida em que todas as obras da UC Digitalis se encontram protegidas pelo Código do Direito de Autor e Direitos Conexos e demais legislação aplicável, toda a cópia, parcial ou total, deste documento, nos casos em que é legalmente admitida, deverá conter ou fazer-se acompanhar por este aviso.

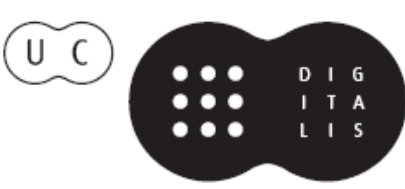




\section{UM OLHAR FREIREANO SOBRE A CONSTRUÇÃO DE POLÍTICAS PÚBLCAS PARA EJA: DOIS EXEMPLOS RECENTES NO BRASIL}

Jorge Teles ${ }^{81}$

\section{Resumo}

Este artigo objetiva refletir sobre a política pública de educação de jovens e adultos no Brasil da primeira década do século XXI, a partir do pensamento de Paulo Freire. Para tal, serão enfocadas duas experiências relevantes de instâncias dialógicas de construção de políticas públicas: a Comissão Nacional de Alfabetização e Educação de Jovens e Adultos (CNAEJA) e a Agenda Territorial de Desenvolvimento Integrado de Alfabetização e Educação de Jovens e Adultos. Estas experiências se constituem em espaços de exercício de consciência crítica e de formação participativa de políticas para a educação de jovens e adultos. Como arenas de elaboração, acompanhamento e avaliação de políticas públicas, ambas apontam para os desafios e possibilidades de políticas elaboradas em bases freireanas. Seus ensinamentos provocam os governos e a sociedade civil sobre inéditos viáveis nestas políticas públicas.

${ }^{81}$ Foi Diretor Nacional de Políticas de Educação de Jovens e Adultos entre 2007 e 2010. Doutorando do Programa de Pós-graduação em Educação da Universidade Federal Fluminense. 


\begin{abstract}
This article aims to reflect on public policy for youth and adult education in Brazil in the first decade of XXI century, from the thought of Paulo Freire. This will be focused two relevant experiences of dialogic instances of construction of public policies: the National Committee for Literacy and Adult Education (CNAEJA) and the Territorial Agenda of Integrated Development of Literacy and Youth and Adult Education. These experiences constitute practice areas of critical awareness and participatory training policies for youth and adult education. As arenas of formulation, monitoring and evaluation of public policies, both experiences point out challenges and possibilities of policies based on the thought of Freire. The lessons awake governments and civil society to the unknown-viable ways in the public policies.
\end{abstract}




\section{Introdução}

O Brasil completa trinta anos de saída de um regime ditatorial. A redemocratização do país foi marcada por um reemergir de movimentos sociais, juntamente com o fortalecimento e (re) organização de grupos de pressão que funcionaram durante o regime de repressão. A abertura política não significou mudança imediata no cenário governamental. Após anos, a primeira eleição presidencial realizada de forma direta, ou seja, com voto popular, deu-se apenas em 1989. Contudo, a aprendizagem democrática continua acontecendo em um país que sofreu com duas ditaduras no século XX.

Do ponto de vista educacional, a situação reproduzia o cenário social mais amplo. Como um reflexo, a educação escolar sofria com uma concepção bancária, como diria Paulo Freire, ratificada pela influência de organismos financeiros internacionais que pressionavam por uma escola de "resultados", no sentido de desempenho estrito no tocante a conteúdos pré-definidos unilateralmente. Esta condução da política educacional afastava-se da proposta freireana, tanto em suas diretrizes quanto em suas formas de construção.

A visão de construção coletiva de política pública, tão cara aos grupos de educação popular que atuavam no Brasil antes do Golpe civil-militar de 1964, não foi retomada com a abertura política. ${ }^{82}$ Apesar dos processos de anistia, do retorno de educadores, intelectuais e formadores de opinião para o país - como foi o caso de Paulo Freire -, a atuação desses sujeitos não garantiu uma mudança significativa na forma em que se dava a construção

82 Cabe frisar que atividades de educação popular continuaram a existir mesmo à margem da política nacional para educação. Após um período de inexistência, foi implantado o Movimento Brasileiro de Alfabetização (MOBRAL) em 1967 e o Ensino Supletivo em 1971 - políticas forjadas sem participação popular. 
política em nível federal ${ }^{83}$. No tocante às experiências estaduais e municipais, houve casos de mudança, como o período em que Freire esteve à frente da Secretaria de Educação do Município de São Paulo ${ }^{84}$. Todavia, estes casos emblemáticos foram raros no país.

Cabe destacar aqui a coordenação de iniciativas dos movimentos pela educação no tocante à construção da Constituição Federal de 1988. Neste sentido, houve avanços consideráveis no texto constitucional, inclusive trazendo a educação como um direito de todos e todas, independentemente da idade do sujeito. A responsabilização do Estado com o provimento das garantias para a fruição do direito à educação de jovens e adultos está posto nesta Carta Magna.

Outro embate se deu no início da década de 90, quando os movimentos se articularam para confecção da legislação específica para a educação básica ${ }^{85}$. Os esforços foram grandes, contudo houve uma reversão, e o texto final da Lei de Diretrizes e Bases da Educação Nacional (LBD/96) ${ }^{86}$, não considerou muitas das contribuições da coletividade.

Neste contexto, a Educação de Jovens e Adultos (EJA) foi recolocada no cenário nacional de modo diferenciado pelos movimentos sociais. Em 1996 houve o reconhecimento da EJA enquanto modalidade da Educação Básica na LDB/96, mas que não significou uma real inclusão dos sujeitos da EJA no rol de beneficiários das políticas e programas da Educação Básica.

Os embates pela transformação da política nacional baseada em um programa com características compensatórias, assistencialistas e

83 Todavia, há de se reconhecer os avanços, por meio da participação popular nos debates constituintes, na criação da Lei de Diretrizes e Bases da Educação Nacional de 1996, na discussão de um fundo para manutenção do Ensino Fundamental (FUNDEF/1996) e no Plano Nacional de Educação 2001/2010.

84 Com a criação do Movimento de Alfabetização de Jovens e Adultos (MOVA) em 1989, parceria entre o governo da Cidade de São Paulo e a sociedade civil.

85 Que compreende todo o sistema escolar anterior ao Ensino Superior no Brasil.

${ }^{86}$ Lei $\mathrm{n}^{\circ}$ 9.394, de 20 de dezembro de 1996. 
bancárias, rumo a outra configuração, mais freireana, foi marcado por avanços e retrocessos. Este Programa tão criticado foi finalizado, todavia o horizonte de vitória alcançado do ponto de vista normativo, com a Constituição Federal de 1988 e a LDB/96 ${ }^{87}$ não se traduziu em uma política nacional de fôlego. Além disto, o veto presidencial à entrada da EJA no Fundo Nacional de financiamento do Ensino Fundamental (FUNDEF) ${ }^{88}$ foi fatal para a estruturação desta modalidade da Educação Básica.

Na segunda metade da década de noventa, a EJA sofreria mais uma vez com a negação do Governo Federal em construir coletivamente a participação do Brasil na V CONFINTEA ${ }^{89}$. O documento preparatório do Brasil foi construído unilateralmente e a participação na conferência se deu de forma isolada dos movimentos sociais pela educação de jovens e adultos. Neste contexto, estes movimentos sociais começaram a se organizar em forma de fóruns estaduais de educação de jovens e adultos ${ }^{90}$.

Após a referida conferência, diante das muitas pressões sociais, ao final da década de 1990 o Governo Federal apresentou resposta tímida, com criação unilateral de dois programas de caráter mais tópico, convertendo "(...) um direito garantido na Constituição em um ato filantrópico" (Barreyro, 2010, p 185), caracterizando "desresponsabilização" do Estado e viés "assistencialista". Não havia

\footnotetext{
87 No tocante à EJA, a LDB/96 traz um texto muito flexível e favorável à adoção de projetos freireanos.

${ }^{88}$ Fundo de Manutenção e Desenvolvimento do Ensino Fundamental e de Valorização do Magistério (FUNDEF). Instituído pela Emenda Constitucional n. ${ }^{\circ}$ 14, de setembro de 1996, e regulamentado pela Lei n. $^{\circ} 9.424$, de 24 de dezembro do mesmo ano, e pelo Decreto $\mathrm{n}^{\circ} \mathbf{2 . 2 6 4}$, de junho de 1997 . Começou a vigorar nacionalmente em $1^{\circ}$ de janeiro de 1998. (http://mecsrv04.mec.gov.br/sef/fundef/funf.shtm ).

89 Conferência Internacional de Educação de Adultos, promovida pela UNESCO, com a participação dos ministros de Estado para educação de todos os países que compõem as Nações Unidas.

90 Para maiores detalhes sobre a constituição destes fóruns, ver: http://www. forumeja.org.br/
} 
uma concepção ampla de direito à educação para todos e todas, tampouco foi contemplada a pluralidade dos sujeitos da EJA.

As novas mudanças no campo político e legislativo foram favoráveis à educação de jovens e adultos, mas não lograram traduzir em formulação e implementação de políticas o que estava garantido na Constituição Federal de 1988 e nas legislações educacionais. O direito foi assumido no papel, mas na prática ele não foi reconhecido, do ponto de vista de atendimento dos sujeitos de direito na EJA. Em relação à forma de construção desta tradução do legal em político-programático, a percepção da importância de uma participação coletiva mais ampla e representativa, do ponto de vista freireano, não foi contemplada neste período de cerca de 15 anos de saída do regime ditatorial.

A ausência de diálogo aberto com a sociedade civil e de articulação institucional, a negação de voz a outros parceiros locais e aos próprios sujeitos de direito, marcaram as definições da Agenda ${ }^{91} \mathrm{e}$ a forma de tradução desta em políticas e programas nesse período. Mesmo com a reorganização dos grupos de pressão (constituição dos fóruns de EJA), este cenário não se alterou significativamente à época. Esta falta de diálogo em nível nacional repercutiu nas esferas estaduais e municipais, de modo geral. Este cenário só começa a se alterar a partir de 2003.

As discussões travadas pela sociedade civil e as experiências de analisar o fenômeno da alfabetização por outros prismas, nacional e internacionalmente, trazem à tona a complexidade do tema e põem em cheque retóricas de "higienização" e visões messiânicas de "erradicação".

91 A discussão de política pública tem na formulação da Agenda um eixo chave. A Agenda reúne os assuntos e problemas sobre os quais o Governo e os atores sociais estão debruçados durante um determinado tempo (Baptista \& Rezende, 2011). Esta é informada pela atuação e interação entre os atores sociais e entre estes e o Governo - frisando que o próprio Governo não se constitui em um grupo homogêneo, mas, pelo contrário, as disputas internas são tão intensas quanto as externas. O estabelecimento da Agenda orienta a alocação de recursos e, consequentemente interfere nas possibilidades de resultados sociais e de ganhos políticos por parte de determinados segmentos. 
Neste contexto, o ano de 2004 é marcado por um reposicionamento do Governo Federal e uma alteração nas relações com os demais atores sociais interessados no tema. Essa nova atitude reflete uma mudança de paradigma no tocante à alfabetização e à EJA, quanto à formulação, condução, acompanhamento e avaliação das políticas públicas.

Neste cenário, aponta-se para a nova postura quanto ao diálogo e participação dos movimentos sociais na construção da política pública $^{92}$, com destaque para duas experiências emblemáticas: a Comissão Nacional de Alfabetização e Educação de Jovens e Adultos (CNAEJA) e a Agenda Territorial de Desenvolvimento Integrado de Alfabetização e Educação de Jovens e Adultos (Agenda Territorial).

Para se entender melhor as características freireanas destas experiências de construção coletiva de políticas cabe retomar alguns conceitos-chave do pensamento de Paulo Freire. Em primeiro lugar, vale frisar que Freire entende a educação como um ato político. Neste sentido, a questão vai muito além de transmitir conteúdos. Mesmo que seja definido no conteúdo programático que a educação deve formar cidadãos críticos, como construir esta criticidade em um processo onde a formulação e a implementação não se dão em bases democráticas?

\section{Pensamento Freireano e construção participativa de políticas públicas}

Para Paulo Freire os homens são seres dotados de consciência, mas cuja consciência está permanentemente em elaboração. Ou seja,

92 Por exemplo, o MEC uniu forças com a sociedade civil para inclusão da EJA no novo fundo de financiamento da Educação Básica, o Fundo de Manutenção e Desenvolvimento da Educação Básica e de Valorização dos Profissionais da Educação (FUNDEB): criado pela Emenda Constitucional $n^{\circ}$ 53/2006 e regulamentado pela Lei $\mathrm{n}^{\circ} 11.494 / 2007$ e pelo Decreto $\mathrm{n}^{\circ}$ 6.253/2007. Substituiu o FUNDEF a partir de 2007 (Teles, 2006). Este novo Fundo trouxe consigo o reconhecimento da EJA enquanto modalidade da Educação Básica. 
ele concebe um sujeito ativo, que é agente, não se submetendo passivamente aos mecanismos sociais que o constituem. Concebendo a formação dos sujeitos em perspectiva dialética, destaca a importância da interação do sujeito com o coletivo e com o social/mundo neste processo formativo - o qual se dá de modo contínuo e inacabado. Esta permanente (re)feitura é característica de um ser que está em constante mutação, em constante troca com o meio, em constante diálogo com o outro, com o contexto que o cerca. A consciência é, portanto, socialmente construída.

Para Freire: "Só somos porque estamos sendo. Estar sendo é a condição, entre nós, para ser" (Freire, 2011, p. 36, 37). Ele considera que a conscientização só pode ocorrer coletivamente. Ninguém se conscientiza sozinho, separado do social. É a interação que vai constituir a consciência. O sujeito está permanentemente imbricado em um fluxo de múltiplas vozes que o constituem, não de forma permanente, tampouco harmoniosamente, sem tensão.

Aqui chegamos ao ponto de que devêssemos ter partido. O do inacabamento do ser humano. Na verdade, o inacabamento do ser ou a sua inconclusão é próprio da experiência vital. Onde há vida, há inacabamento. Mas só entre mulheres e homens o inacabamento se tornou consciente. (Freire, 1996, p. 50)

Os homens são seres inconclusos e têm consciência de sua inconclusão. Exatamente esta consciência de sua inconclusão que está na base da Educação, enquanto fenômeno exclusivamente humano, tornando-a um "quefazer" permanente: "a inconclusão que se reconhece a si mesma, implica necessariamente a inserção do sujeito inacabado num permanente processo social de busca." (Freire, 2001a, p. 61)

De um lado, a compreensão mecanicista da História, que reduz a consciência a puro reflexo da materialidade, e de outro, o 
subjetivismo idealista, que hipertrofia o papel da consciência no acontecer histórico. Nem somos, mulheres e homens, seres simplesmente determinados nem tampouco livres de condicionamentos genéticos, culturais, sociais, históricos, de classe, de gênero, que nos marcam e a que nos achamos referidos. (Freire, 2011, p. 111)

Além disto, Freire destaca a questão política do desenvolvimento desta consciência. Para Freire, existem níveis de conscientização, que organizam as leituras de mundo em patamares relacionados aos processos de tomada de consciência política.

Na obra "Conscientização: teoria e prática da libertação" (Freire, 2001a) este assunto é abordado apontando para a diferença entre uma primeira aproximação espontânea do homem em relação ao mundo, prefigurando uma posição que Freire denomina de "ingênua", e aquilo que designa como conscientização. "A este nível espontâneo, o homem, ao aproximar-se da realidade, faz simplesmente a experiência da realidade na qual ele está e procura" (Freire, 2001a, p. 30).

$\mathrm{O}$ "mutismo" de que trata Freire na fase de ingenuidade da consciência não significa ausência de resposta, mas carência de criticidade nesta resposta. Após o momento de tomada de consciência, os sujeitos poderão vir a desenvolvê-la criticamente - alcançando o que Freire denomina de consciências transitivas críticas.

A conscientização implica, pois, que ultrapassemos a esfera espontânea de apreensão da realidade, para chegarmos a uma esfera crítica na qual a realidade se dá como objeto cognoscível e na qual o homem assume uma posição epistemológica. (Freire, 2001a, p. 30)

No âmbito deste desenvolvimento crítico, a realidade vai se "des-velando", por meio de um processo dialético de ação e reflexão. "Esta unidade dialética constitui, de maneira permanente, o modo de ser ou de transformar o mundo que caracteriza os homens" 
(Freire, 2001a, p. 30). Isto demanda uma inserção crítica do homem na história, assumindo o papel de sujeito que faz e refaz o mundo, (re)criando sua existência a partir de e com os materiais que a vida oferece."(...) a situação concreta em que estão os homens condiciona a sua consciência do mundo e esta as suas atitudes e o seu enfrentamento" (Freire, 2013, p. 175). Ou seja, isto implica em uma relação entre consciência e mundo, historicamente imbricados.

Quando as políticas públicas são analisadas a partir desta linha de pensamento, pode-se perceber que a política precisa refletir a relação entre consciência e mundo, historicamente imbricados. Isto traz implicações para o processo de desenho desta política, que abrange tanto a formulação, quanto a implementação e a avaliação desta mesma política. Diante disto, a política não pode se constituir em um arcabouço estático, engessado, fechado, que se vê como pronto, completo e resiste a novos olhares. Pelo contrário, a política tem que estar sendo. Ela tem que estar em constante processo de (re)construção, orientada criticamente pelas consciências dos sujeitos envolvidos. A política deve se configurar, então, como um "que fazer" permanente, enquanto processo social perene de busca de objetivos acordados entre os sujeitos.

Analisando com olhar freireano, uma política deve responder a um processo formativo de sujeitos em permanente construção. Construir tal política demanda envolver os sujeitos, imbricá-los no processo, na condição mesmo de sujeitos. Ouvir-lhe a voz, e expô-lo às outras vozes, de modo intencionalmente voltado para o desenvolvimento da conscientização. Inseri-los criticamente no processo, porém em todo o processo, desde sua formulação, até a avaliação, passando pela implementação da política. Esta política deverá enxergar o sujeito como aquele que faz e refaz esta mesma política. Ao imbricar estes sujeitos, a política deverá promover interações que propiciem desenvolvimento crítico das consciências. Esta política deverá atuar como instância de provocação coletiva ao desenvolvimento da 
conscientização. Ou seja, ela deverá estar voltada para a tomada de consciência política.

A partir da configuração do sujeito como inacabado e da relação deste sujeito com a alteridade como sendo constitutiva desse mesmo sujeito (e também do outro), Freire postula a responsabilidade do sujeito na construção de um mundo ético. Freire reforça o tom neste ponto, devido a sua preocupação com a práxis - sua atividade militante está explicita em todos os seus trabalhos.

Paulo Freire também atribui um papel de destaque ao futuro na compreensão da agência do sujeito no presente. O futuro ganha um papel diferenciado no presente - lugar de utopia para Freire. Ele reforça a necessidade de reconhecermos que a História não é tempo de determinismo, mas sim de possibilidade. A passagem dos homens por este mundo não está pré-determinada. Freire afirma que o futuro não é inexorável, o futuro é problemático.

Só há História onde há tempo problematizado e não pré-dado. A inexorabilidade do futuro é a negação da História. (...) A desproblematização do futuro numa compreensão mecanicista da História, de direita ou de esquerda, leva necessariamente à morte ou à negação autoritária do sonho, da utopia, da esperança. (Freire, 2011, p. 81)

O sujeito assume um papel de (re)criador da história, realizador de transformações, assumindo um compromisso histórico de denunciar estruturas desumanizantes e anunciar estruturas humanizantes. Desta forma, ao assumir este compromisso histórico, o sujeito assume um papel de "fator utópico" - isto exigirá dele conhecimento crítico, pois a utopia é um ato de conhecimento. A conscientização, portanto, implica em utopia, em um olhar o mais crítico possível da realidade, ao mesmo tempo em que toma posse dela, também a desmitifica. (Freire, 2001a) 
Uma política construída em bases freireanas deverá contribuir para a tomada de posse da realidade pelos sujeitos, ao mesmo tempo em que desmitifica esta mesma realidade, de modo crítico. A elaboração desta política se dá como resposta à problematização ao mesmo tempo em que problematiza o presente/futuro. Não pode haver espaço para simplificação das respostas aos problemas sociais, não pode acatar visão mecanicista do funcionamento da sociedade e, consequentemente, do tipo e da forma de intervenção via política pública.

A política deverá estar inserida no movimento de reconhecer e atender às possibilidades postas no contexto histórico, de aprender com o passado e ir (re)construindo o futuro. Neste sentido, abre-se espaço para a política enquanto fomentadora do sonho, da esperança, da utopia - ao mesmo tempo em que responde a eles, dialeticamente. Enxergar a política como lugar da utopia é reconhecer nela um espaço propiciador de desenvolvimento dos sujeitos enquanto "fatores utópicos". Portanto, a política deverá funcionar como resultado e, ao mesmo tempo, como estimuladora de inéditos viáveis.

Pensar inéditos viáveis não é tarefa de uma elite intelectual, a qual se sente capaz e responsável por pensar o futuro da sociedade. Pelo contrário, estes inéditos viáveis devem ser fruto de construção coletiva, de interação dos sujeitos, de análise crítica conjunta sobre possibilidades e a respeito das ações a serem adotadas. Para onde ir e como chegar lá deverão ser pensados coletivamente e as respostas a estas questões deverão ser colocadas pela coletividade, pelos sujeitos, que devem ser mutuamente estimulados, de modo crítico e permanente.

Neste ponto, cabe destacar que Freire também considera a inter-relação como constitutiva das subjetividades. Ele coloca que estas mesmas subjetividades somente ganham concretude na linguagem. Para Freire, os homens se fazem no diálogo - este encontro de homens mediatizados pelo mundo. Este "encontro" não significa qualquer estabelecimento de contato entre dois seres, pelo contrário, envolve um relacionar-se onde estão imbricadas a pluralidade 
de vozes, a transcendência e a temporalidade, além de criticidade e consequência (Freire, 2008, p. 47). Segundo ele, não se pode pensar nem pelos outros, tampouco para os outros, assim como também não há como pensar sem os outros. O diálogo traz os homens à feitura um com o outro, não reduzindo ou subjugando um pelo outro. Não é algo dado, concedido, de modo unilateral, mas, pelo contrário, é construído mutuamente na intersubjetividade, que traz uma concepção de mundo e demarca os lugares do falante e do ouvinte. Esses homens ganham significação enquanto tais pelo diálogo, pela palavra que diz o mundo, pela palavramundo [ênfase adicionada].

Na verdade, não há eu que se constitua sem um não eu. Por sua vez, o não eu constituinte do $e u$ se constitui na constituição do eu constituído. Desta forma, o mundo constituinte da consciência se transforma em mundo da consciência, um percebido objetivo seu, ao qual se intenciona. (Freire, 2013, p. 99, grifos no original)

O eu dialógico, pelo contrário, sabe que é exatamente o $t u$ que o constitui. Sabe também que, constituído por um $t u$ - um não eu - esse $t u$ que o constitui se constitui, por sua vez, como $e u$, ao ter no seu eu um $t u$. Desta forma, o e $u$ e o $t u$ passam a ser, na dialética destas relações constitutivas, dois $t u$ que se fazem dois eu. (Freire, 2013, p. 227, grifos no original)

Diante do exposto, uma política edificada em bases freireanas deverá ser dialógica. Isto não se resume a deixar que as pessoas coloquem sua opinião, ou ouvir os beneficiários da política, para saber se estão satisfeitos. Na realidade, a questão transcende (e muito) a consulta de satisfação. Tampouco significará apenas uma boa estrutura de "serviço de atendimento ao cliente". Pelo contrário. O sujeito não deverá ser alijado do processo da política. A participação desse sujeito neste processo significa que a política 
deverá fomentar o relacionamento, assumindo a pluralidade de vozes como sua constitutiva, de modo perene e consequente. Não se pode pensar esta política à revelia dos sujeitos que serão alvo da mesma. Uma política não deve apenas "contemplar" um grupo de sujeitos, mas chamá-los para assumir um espaço de protagonismo em sua (re)construção. Sem a participação dos sujeitos enquanto sujeitos críticos, não há como desenhar uma política em bases freireanas. A política deverá propiciar aos sujeitos dizerem sua palavra, a palavramundo, ao mesmo tempo em que respondem consequentemente a esta mesma palavra.

Cabe elucidar que a dialogia entendida enquanto relação entre "eu" e "tu" não significa consenso ou harmonia. Pelo contrário, há polêmica e tensões, mas ambos os polos se constituem concomitantemente - eu-tu: um não existe sem o outro. Isto significa, no campo da política pública, que nem sempre haverá consensos, que as palavras nem sempre convergirão, que não se conseguirá que todos os sujeitos tenham sua opinião implementada. Contudo, o processo deve ser democrático e participativo, com criticidade e consequência. Lembrando que não deve haver visão inexorável, ou seja, as decisões devem ser temporalmente encaradas, podendo vir a mudar, a partir das interações dos sujeitos na coletividade. As políticas são historicamente construídas pelos sujeitos históricos, é claro, mas cabe aos sujeitos tomarem as rédeas do processo de construção dessas políticas, de modo crítico e consequente - cabendo à interação entre esses sujeitos as mudanças e alterações de rumo das políticas. Portanto, deve se ter sempre em mente que se trata de um espaço de disputas, e que a questão maior diz respeito à forma como cada sujeito participa (ou não) do processo.

A partir das colocações acima, desponta com clareza a necessidade de não apenas implementar uma política em bases freireanas, mas a própria concepção da política deve ser estruturada a partir dos conceitos expostos acima. Neste sentido, pensar em como a 
política é formulada ganha destaque. O espaço de formulação da Agenda pública e a tradução desta Agenda em políticas públicas necessitam de ter bases freireanas, a fim de resultar em políticas com estas mesmas características. A criação de arenas de reflexão crítica sobre políticas públicas que se constituam em espaços de diálogos, em permanente (re)construção e que sejam resultado, ao mesmo tempo em que fomentem inéditos viáveis, é um alvo que deve ser buscado pelo Governo e pela sociedade civil, em uma perspectiva de política pública educacional freireana.

\section{A CNAEJA como lócus dialógico}

A relação entre o Governo Federal e os movimentos sociais no Brasil passou por uma mudança significativa na primeira década do século XXI. Abriram-se espaços para diálogos em diferentes áreas do Governo Federal. Foram criados colegiados, no intuito de ampliar as conversas sobre as políticas públicas no âmbito federal. Estes espaços tanto se referiam a maiores tratativas com estados, Distrito Federal e municípios, quanto com movimentos e organizações da sociedade civil.

No campo das políticas educacionais, foi lançado o Programa Brasil Alfabetizado (PBA) em 200393, o qual instituiu a Comissão Nacional de Alfabetização ${ }^{94}$. Formada para assessorar o Ministério da Educação (MEC) nas questões pertinentes ao PBA, cumprindo um papel de instância consultiva ${ }^{95}$, esta comissão seria composta por

93 Decreto Presidencial $\mathrm{n}^{\circ} 4.834$, de 8 de setembro de 2003.

${ }^{4} \mathrm{Na}$ realidade, em 1989 já havia sido criada uma Comissão Nacional de Alfabetização, inicialmente com o próprio Paulo Freire à frente, a qual foi esvaziada em 1990 com as mudanças no Governo Federal.

95 O que difere da Comissão Nacional de Alfabetização e de Educação Assistemática, criada pelo Decreto ${ }^{\circ} 59.667$, de 5 de dezembro de 1966, no período da Ditadura 
"personalidades reconhecidas nacionalmente e por pessoas indicadas por instituições e entidades representativas da área educacional, de âmbito nacional"96. Como pode ser constatado, a função precípua desta comissão era congregar pessoas que pudessem contribuir para as discussões sobre o PBA. A presidência desta comissão foi atribuída ao Ministro da Educação, sendo substituído em caso de ausência ou impedimento, pelo Secretário ${ }^{97}$ Extraordinário de Erradicação do Analfabetismo.

Posteriormente, com a substituição da Secretaria Extraordinária de Erradicação do Analfabetismo pela Secretaria de Educação Continuada, Alfabetização e Diversidade (SECAD), foi renovada e fortalecida essa instância de diálogo nacional, a qual foi ampliada do foco de programa de alfabetização para as questões mais amplas de educação de jovens e adultos, em um claro movimento de elevação de institucionalidade e iniciativa republicana de maior comprometimento, visando responsabilização social das instâncias de decisão no tocante à EJA. Esta nova configuração recebeu o nome de Comissão Nacional de Alfabetização e Educação de Jovens e Adultos - CNAEJA ${ }^{98}$.

A CNAEJA foi composta de modo a representar os principais grupos de sujeitos envolvidos com educação de jovens e adultos, em suas diversas instâncias. Neste sentido, havia segmentos ligados ao Governo Federal, internos ao MEC e representantes de outros ministérios; estavam representados os outros dois níveis do sistema político federativo do Brasil (Estados e Municípios), tanto seus executivos responsáveis pela educação, como os conselhos de educação; também estava representada a sociedade civil, pelos diversos segmentos sociais que compõem os sujeitos da educação

Civil-militar no Brasil, que apresentava cunho mais voltado para gestão do "plano complementar de educação para analfabetos".

96 Art. $2^{\circ} \S 1^{\circ}$ do Decreto $n^{\circ} 4.834 / 03$.

97 Cargo equivalente ao que em alguns países é denominado de vice-ministro.

98 Conforme Decreto Presidencial $n^{\circ} 5.475$, de 22 de junho de 2005. 
de jovens e adultos; a academia e os formadores de educadores também estavam presentes; por fim, havia assento para os organismos internacionais que militam no tema.

A composição das representações do Governo Federal era constituída pela atuação nesta comissão dos seguintes grupos (alguns foram inseridos posteriormente à criação da mesma): MEC (SECAD, Secretaria de Educação Básica e Secretaria de Educação Tecnológica), Secretaria Nacional de Economia Solidária (Ministério do Trabalho e Emprego), Ministério da Cultura, Secretaria Nacional da Juventude.

A composição das representações dos governos estaduais, distrital e municipais era constituída pela atuação nesta comissão dos seguintes grupos (alguns foram inseridos posteriormente à criação da mesma): Conselho Nacional de Secretários de Educação, União Nacional dos Dirigentes Municipais de Educação, Fórum dos Conselhos Estaduais de Educação, Fórum dos Conselhos Municipais de Educação.

Como representantes dos profissionais que atuam na área da educação, havia a Confederação Nacional dos Trabalhadores em Educação, a representação das Instituições de Ensino Superior e a Associação Nacional de Pós-Graduação e Pesquisa em Educação - ANPED, que reúne os pesquisadores da área.

Os sujeitos da educação de jovens e adultos estavam representados pelos seguintes grupos (alguns foram inseridos posteriormente à criação da mesma): pelo segmento de Juventude, por representantes dos Movimentos de Negros, dos Povos Indígenas, da Confederação Nacional dos Trabalhadores na Agricultura, do Movimento dos Trabalhadores Rurais Sem Terra e do Movimento dos Atingidos por Barragens.

As organizações e movimentos da sociedade civil mais especificamente atuantes na EJA estavam representados pelos seguintes grupos (alguns foram inseridos posteriormente à criação da mesma): representantes das organizações não-governamentais com experiência em EJA (Ação Educativa) e em Educação Ambiental, representan- 
tes dos Movimentos de Alfabetização de Jovens e Adultos - MOVA Brasil, e dos Fóruns de EJA.

Os organismos internacionais que militam na área da educação, em especial com educação de jovens e adultos estavam representados pela UNESCO e pela Organização dos Estados Iberoamericanos - OEI.

Desta forma, a constituição da CNAEJA foi delineada de modo plural e participativo, para contemplar a diversidade dos sujeitos da educação de jovens e adultos, bem como das instituições relacionadas à área. A participação desses segmentos nas reuniões era maciça e frequentemente faziam a interlocução com os demais agentes não diretamente atuantes neste espaço de discussão e trabalho. A Comissão se reunia ordinariamente duas vezes ao ano (uma por semestre), porém havia uma série de reuniões extraordinárias, acordadas de forma a atender à dinâmica das questões sociais e políticas postas no momento. Por vezes, o coletivo era convocado integralmente, havendo também situações onde o coletivo entendia que uma parte da Comissão deveria atuar mais presencialmente, mantendo diálogo com os demais componentes. Tal fato deu uma maior flexibilidade à participação da Comissão em diferentes assuntos relativos às políticas. Tal desenho e atuação flexível fazia com que a Comissão tivesse uma atuação intensa e tempestiva nas questões referentes às políticas de educação de jovens e adultos.

Cabe aqui destacar também a enorme disponibilidade demonstrada por todos os participantes desta Comissão em atuar em favor da (re)construção de políticas em bases freireanas para a educação de jovens e adultos no Brasil. Os representantes tinham voz e faziam valer seu direito à palavra. Dizendo sempre a sua palavra, colocavam suas posições sobre as políticas e mantinham diálogo com suas bases a respeito da condução do processo e das decisões tomadas. Isto transformou esta arena em um espaço de avaliação critica das políticas e de intervenção nas diversas instâncias de formulação, implementação e análise das políticas públicas para 
educação de jovens e adultos. Sendo sempre respeitado o lugar e as responsabilidades de cada instituição, o papel de cada uma era estimulado, por meio de reflexão crítica e consequente, buscando sempre o avanço viável. Isto não significa que sempre houve consenso, ou que a opinião de cada um foi sempre implementada imediatamente, mas o processo como um todo sempre foi dialógico e respeitoso, crítico e construtivo.

A atuação da CNAEJA foi crucial nos debates, análises, encaminhamentos e orientações para as políticas públicas de educação de jovens e adultos, bem como para o posicionamento do país no cenário internacional. Por exemplo, nos debates com o Conselho Nacional de Educação - CNE, que resultaram na Resolução CNE $n^{\circ}$ 3, de 15 de junho de 2010, que "institui Diretrizes Operacionais para a Educação de Jovens e Adultos nos aspectos relativos à duração dos cursos e idade mínima para ingresso nos cursos de EJA; idade mínima e certificação nos exames de EJA; e Educação de Jovens e Adultos desenvolvida por meio da Educação a Distância".

Cabe destacar os preparativos do Brasil para a participação na VI CONFINTEA ${ }^{99}$. O país se voluntariou a hospedar a Conferência - oferta aceita pela UNESCO. O Governo federal, por meio do MEC, coordenou um processo nacional de diálogo com os sujeitos da EJA, como movimento preparatório para esta conferência. Nestas atividades preparatórias, o MEC envolveu pessoas e instituições que atuam na $\mathrm{EJA}^{100}$. Este período se constituiu como um tempo de estreitar relações entre o Governo Federal, Estados e Municípios, especialistas em educação e representantes dos mais diversos âmbitos educativos - formais e não formais ${ }^{101} \mathrm{em}$ todo o país.

\footnotetext{
99 Os documentos relativos à CONFINTEA estão disponíveis em www.mec.gov.br.

100 As demais áreas do Governo também se organizaram e contribuíram para o debate da VI CONFINTEA e para as Agendas Territoriais.

101 Neste artigo assumimos as definições de educação formal e educação não formal da Classificação Internacional Padrão da Educação (UNESCO, ISCED 1997).
} 
Entre 2007 e 2009, o MEC, em parceria com os sistemas de ensino formal e movimentos sociais vinculados à educação não formal, com destaque para o papel dos Fóruns de EJA ${ }^{102}$, promoveu 33 encontros preparatórios ${ }^{103}$ à VI CONFINTEA - 27 estaduais ${ }^{104}$, cinco regionais e um nacional ${ }^{105}$. Participaram desse amplo debate gestores, educadores, estudantes, organizações não governamentais e sindicais, universidades, coletivos e colegiados vinculados à educação formal e não formal. Foram eleitos delegados para participar do processo, e os mesmos acompanharam cada uma das etapas. Foram apontadas questões, análises da situação e sugestões para melhorias - as quais foram ampla e democraticamente debatidas e votadas, vindo a constituir o documento preparatório brasileiro para a VI CONFINTEA (Brasil, 2009).

O objetivo político desta iniciativa foi gerar um diagnóstico aprofundado da situação da EJA em cada uma das 27 Unidades da Federação, fortalecer os laços e compromissos políticos entre os Governos e a sociedade civil, bem como reconhecer voz e espaço para que os movimentos sociais e sujeitos de direito expressassem suas visões.

A participação do Brasil na Conferência Latino-americana e na própria VI CONFINTEA foi marcada pela presença atuante dos membros da CNAEJA e por uma parceria entre Governo e Sociedade Civil que resultou em destaque pela UNESCO da experiência brasileira como exemplo para os outros países.

102 Frequentavam os Fóruns entidades da sociedade civil, órgãos de governo, movimentos sociais, universidades, especialistas e interessados. Seu formato aberto e participativo foi decisivo para reunir atores distintos e formular propostas que fizeram avançar as políticas de educação de jovens e adultos no país.

103 Estes encontros foram precedidos de cinco Oficinas Regionais de Formação em Organização e Análise de Dados, que subsidiaram diagnósticos estaduais da EJA.

${ }^{104} \mathrm{Em}$ cada um desses encontros foram reunidos entre 80 e 600 participantes de diferentes segmentos interessados no tema.

105 O Encontro Nacional contou com 300 participantes, vindos como delegados de cada um dos estados e do Distrito Federal; das representações do Grupo de Trabalho Interno do MEC (que reúne os vários órgãos envolvidos na construção da política de EJA); do Grupo de Trabalho Interministerial; do CNE; e da CNAEJA. 


\section{A Agenda Territorial de Desenvolvimento Integrado de Alfabetização e EJA}

Entendendo a dimensão política onde estão inseridas as decisões relativas à gestão das políticas para EJA ${ }^{106}$, a SECAD propôs a criação das Agendas Territoriais de Desenvolvimento Integrado de Alfabetização e EJA (Agendas Territoriais), em franco diálogo com os movimentos sociais e poderes locais. Estas Agendas são uma proposta de articulação territorial das ações para EJA, com o intuito de potencializar a utilização dos recursos e elevar a eficiência, eficácia e qualidade das atividades, por meio de:

a) Elaboração de diagnósticos sobre demanda e condições de oferta para EJA, por Unidade da Federação;

b) Proposição de ações de cada uma das instituições participantes, de acordo com suas respectivas atribuições e responsabilidades institucionais, visando o atendimento das recomendações do Documento Base Nacional para VI CONFINTEA e de resposta aos desafios identificados no diagnóstico;

c) Acordos para a criação de uma mesa permanente de trabalho (comissão), com a participação das instituições presentes e outras, de modo a compartilhar estratégias e ações para a garantia do direito à educação de qualidade para jovens e adultos $^{107}$.

106 Por exemplo, o financiamento para EJA também foi beneficiado pelas estratégias de articulação: a presença da EJA no Plano de Ações Articuladas (PAR/MEC) e no FUNDEB, com elevação do percentual, representam um aporte disponível para a EJA significativo. Contudo, cabe às gestões estaduais, distrital e municipais gerirem adequadamente as fontes e aplicações destes recursos.

107 Para maiores detalhes sobre a estratégia da Agenda Territorial ver Lazaro, Teles \& Silva (2014). Para entender a dinâmica da Agenda e acompanhar uma experiência estadual de implementação da mesma, ver Lima, Correia \& Burgos (2014). 
Para levar a cabo a proposta de articulação territorial, foram feitas reuniões com governadores e prefeitos, que culminaram com a realização de um Pacto com Governadores, que fortalecia as Agendas Territoriais. O próprio MEC passou a utilizar as articulações interministeriais para incentivar atitudes similares entre as áreas nos níveis estadual, distrital e municipal.

A adoção da estratégia das Agendas Territoriais esteve imbricada com as políticas implementadas pelo $\mathrm{MEC}^{108}$. Esta era uma indução do Governo Federal que apresentava dois objetivos: fomentar diretamente as Agendas nas Unidades da Federação, e dar o exemplo aos governos estaduais e distrital, visando maior adesão a esta estratégia. Dadas as diferenças entre as realidades locais no país, a adesão à Agenda Territorial ocorreu de modo heterogêneo. Cabe lembrar as observações de Freire:

[...] uma mesma compreensão da prática educativa, uma mesma metodologia de trabalho não operam necessariamente de forma idêntica em contextos diferentes. A intervenção é histórica, é cultural, é política. É por isso que insisto tanto em que as experiências não podem ser transplantadas mas reiventadas. Em outras palavras, devo descobrir, em função do meu conhecimento tão rigoroso quanto possível da realidade, como aplicar de forma diferente um mesmo princípio válido, do ponto de vista de minha opção política. (Freire, 2001b, p. 26)

Por isto a estratégia das Agendas Territoriais não foi implantada diretamente pelo Governo Federal em cada Unidade da Federação. Pelo contrário, apesar de lançar mão do poder indutivo que possui,

108 Inclusive em termos de fomento para a Agenda Territorial (comissões, elaboração dos diagnósticos locais etc.). Por exemplo, as resoluções emitidas para o Programa Brasil Alfabetizado previam repasse de recursos para executar ações relativas à Agenda Territorial. 
o MEC em momento algum impôs a formação da Comissão. Isto pode ser comprovado pela existência de determinados Governos Estaduais que resistiram terminantemente à implantação da Comissão - a despeito inclusive do fato do próprio Governo Federal dar o exemplo, em seu trato com a CNAEJA. Essas forças retrógradas não perceberam a importância desta ação política e de sua inserção em um contexto maior de promoção de uma educação cidadão, desde a concepção da política educacional até sua avaliação, em bases participativas. Não reconheceram, como diria Freire, "que é impossível estar no mundo, fazendo coisas, influenciando, intervindo, sem ser criticado" (2001b, p. 31).

Cabe frisar que a própria Agenda Territorial está inserida dialeticamente em uma estratégia maior de condução da política pública a partir de parcerias intragoverno, intergovernamental e com a sociedade civil. Neste sentido, ela reflete e amplia a atuação da CNAEJA, no plano territorial dos Estados e do Distrito Federal. Portanto, a relação entre estes espaços de diálogo, ao mesmo tempo arenas da prática política e instâncias colaborativas para a formação destas mesmas práticas democráticas, exerce um papel propício à geração de políticas de cunho freireano.

Estes dois espaços foram pensados coletivamente como arenas para o exercício da cidadania, para a prática conjunta de direitos e deveres que caracterizam o fruto do processo educativo enquanto formação crítica do sujeito de direito. A relação entre educação e política, do ponto de vista freireano, transcende a questão conteudista e transforma a prática cotidiana dos sujeitos, em suas interações sociais. Pensar a formulação, implementação e avaliação de políticas públicas a partir de coletivos de diálogo é, não só pertinente, como crucial para a formação e exercício pleno da cidadania.

Para Freire, "cidadão significa indivíduo no gozo dos direitos civis e políticos de um Estado" e "cidadania tem que ver com a condição de cidadão, quer dizer, com o uso dos direitos e o direito 
de ter deveres de cidadão" (2001b, p. 25). A conquista de espaços de construção coletiva da política de educação de jovens e adultos se constitui como um reconhecimento dessa via de mão dupla, onde se têm direitos, e há de se exercê-los, mas igualmente se têm deveres, e há de se cumpri-los. A Comissão da Agenda Territorial visa convocar os sujeitos de direitos e de deveres a exercitar seu direito em uma atuação participativa na construção da política. Porém, também visa chamar à responsabilidade as instituições governamentais locais e da sociedade civil para seus deveres no tocante ao cumprimento do direito constitucional à educação, ao trabalho, à cultura dos jovens e adultos.

\section{Saberes de Experiência Feitos}

De modo transversal a estas experiências está um estilo de gestão que difere dos governos dos anos 90, cuja característica democrática e republicana marcaram a gestão de 2004 a 2010: a parceria com os movimentos sociais - mais especificamente com os Fóruns de EJA, no caso, e com as coordenações de EJA nas redes públicas dos estados e das capitais. O diálogo freireano entre a União, Estados, Distrito Federal e Municípios e sociedade civil é decisivo para o reconhecimento público do direito à educação e para a ampliação e melhoria das condições de oferta educacional.

Em suma, estas duas experiências demonstram que o período em questão foi marcado por: construção coletiva da política com finalidade de fortalecer os atores sociais; diálogo permanente com movimentos da sociedade civil; reuniões regulares com gestores de EJA; e, criação de espaços de discussão ${ }^{109}$. Juntamente com a

109 Além da participação e apoio em vários outros espaços de diálogo, tais como os Encontros Nacionais de Educação de Jovens e Adultos (ENEJA), Seminários de 
preparação para a VI CONFINTEA, que funcionou como processo de organização do campo e da dimensão nacional do projeto, estes canais de diálogo freireano serviram para, em primeiro lugar reafirmar o direito à educação das populações jovens e adultas, e também auxiliar na construção, na análise crítica e na exposição do descontentamento com determinados aspectos. Acima de tudo, marcaram este período como resultado de atuação coletiva - participativa e respeitosa dos posicionamentos individuais e das atribuições de cada sujeito e instituição envolvidos. Porque só haverá garantia de direitos na educação de jovens e adultos com a ação e participação dos sujeitos de direito.

As mudanças que ocorreram nas políticas de EJA na primeira década do século XXI apontam para o fortalecimento da responsabilidade pública local, para a descentralização do poder de decisão, valorização da diversidade, construção coletiva das políticas, fortalecimento dos sujeitos locais, diálogo permanente e adequado uso dos mecanismos de financiamento. Os espaços de diálogo foram fortalecidos, tendo como base princípios freireanos - tais como a CNAEJA e a Agenda Territorial.

As experiências da CNAEJA e da Agenda Territorial demonstram que a gestão participativa tem um tempo de aprendizagem social. É necessário investir nesse aprendizado, todos crescem com ele. Ou seja, estes espaços de diálogo sobre políticas públicas também se constituem como espaços educativos, propiciando o exercício da consciência crítica e igualmente contribuindo para a tomada de consciência. Espaços de compartilhamento e (re)criação do conhecimento, de formação política, de manifestação ética e procura da boniteza do ser em permanente formação na relação eu-tu.

formação de educadores de jovens e adultos, Encontros da ANPED, Encontros sobre Educação em Prisões, Congresso Internacional da Cátedra de EJA, Congresso de Materiais Didáticos e Literários para EJA, dentre outros. 
Por outro lado, também não podemos esquecer o alerta deixado por Freire (2001b) sobre as limitações de toda e qualquer prática social e histórica. A compreensão crítica desses limites, dentro de um contexto tempo-espacial, traz à tona a lembrança de que os ganhos se dão no exercício da luta política, e que estes ganhos não estão garantidos ad infinitum [ênfase adicionada], mas devem ser reforçados, revisados e reestabelecidos, em um cenário de permanente transformação e de inacabamento dos sujeitos. As próprias conquistas inéditas que se tornaram viáveis tem que ser tensionadas em prol da consolidação dos avanços, mas também de pensar e provocar outros inéditos viáveis.

Neste sentido, não se pode tomar a priori [ênfase adicionada], nem estaticamente as experiências de construção coletiva de política pública. Os saberes relacionados à gestão participativa são construídos a partir das experiências vividas e refletidas criticamente, ou seja, saberes de experiência feitos [ênfase adicionada], - a partir da compreensão de que somos seres inacabados, que dependemos uns dos outros para nos constituir enquanto sujeitos e que somos (re)criadores de nossa história. Estas perspectivas trazem desafios para a política pública que não se solucionam imediatamente. Elas necessitam de tempos de aprendizagem e de experimentação, de iniciativas e de invenções, de tentativas e amadurecimentos.

A tomada de consciência coletiva requer uma postura do poder público, das instituições envolvidas e da sociedade civil no tocante à política pública que torna imprescindíveis estes espaços de diálogo e construção conjunta. Há de se ter paciência pedagógica e histórica para edificar a muitas mãos a política de educação de jovens e adultos que se quer reconhecedora dos sujeitos de direitos. Pensar política pública em bases freireanas é pensarmos juntos o impensável, percorrendo os caminhos que trarão à lume tal utopia. O sonho de política pública de Estado para EJA passa obrigatoriamente pela mobilização dos sujeitos sonhadores, para 
sonharem e construírem juntos a realização deste sonho. Será sonhando juntos que produziremos os saberes necessários para avançarmos na experiência concreta. Sonhemos, pois!

\section{Referências bibliográficas}

Baptista, T. W. F., \& Rezende, M. (2011). A ideia de ciclo na análise de políticas públicas. In R. A. Mattos \& T. W. F. Baptista. Caminhos para análise das políticas de saúde (pp. 138-172).

Barreyro, G. B. O. (2010). Programa Alfabetização Solidária: terceirização no contexto da Reforma do Estado. Educar em Revista, 38, 175-191: Curitiba: Editora UFPR

Brasil. Ministério da Educação. Secretaria de Educação Continuada, Alfabetização e Diversidade. (2009). Documento Nacional Preparatório à VI Conferência Internacional de Educação de Adultos (VI CONFINTEA). Brasília: Ministério da Educação (MEC).

Lima, M. N. S., Correia, M. Z. S., \& Burgos, M. P. (Orgs.). (2014). Agenda Territorial de Desenvolvimento Integrado de Alfabetização e Educação de Jovens e Adultos do Estado de Pernambuco: breve histórico. Recife: Centro Paulo Freire - Estudos e Pesquisas.

Freire, P. (;2013). Pedagogia do oprimido (54a edição). Rio de Janeiro: Paz e Terra.

Freire, P. (2011). Pedagogia) da autonomia. Saberes necessários à prática educativa ( $43^{\mathrm{a}}$ ed.). Rio de Janeiro: Paz e Terra.

Freire, P. Educação como prática da liberdade. (2008). São Paulo: Cortez.

Freire, P. Conscientização: teoria e prática da libertação. Uma introdução ao pensamento de Paulo Freire. (2001a). São Paulo: Centauro.

Freire, P. Política e Educação. (2001b). São Paulo: Cortez.

Heniques, R. \& Ireland, T. (2005). A Política de Educação de Jovens e Adultos no Governo Lula. In Unesco, Mec, Raaab. Construção Coletiva: Contribuições à Educação de Jovens e Adultos. [Coleção Educação para Todos]. (Vol.3). Brasília: UNESCO, MEC/RAAAB.

Lazaro, A. (2012). Ou a educação se dispõe a ter uma dimensão civilizatória ou ela renuncia ao seu papel. Cadernos Cenpec, 2(2), 131-170.

Lazaro, A., Teles, J. L., \& Silva, M. (2014). A Agenda Territorial de Desenvolvimento Integrado de Alfabetização e Educação de Jovens e Adultos no Brasil. In M. N. S. Lima, M. Z. S. Correia \& M. P. Burgos. (Orgs.). Agenda Territorial de Desenvolvimento Integrado de Alfabetização e Educação de Jovens e Adultos do Estado de Pernambuco: breve histórico. (pp. 25-43). Recife: Centro Paulo Freire - Estudos e Pesquisas.

SESI \& UNESCO. (1999). Conferência Internacional sobre Educação de Adultos (V: 1997: Hambugo, Alemanha): Declaração de Hamburgo: agenda para o futuro. Brasília: SESI/UNESCO. Retirado de http://unesdoc.unesco.org/ images/0011/001161/116114por.pdf 
Teles, J. (2006). Educação e Políticas Públicas: Para Além das Metas do Milênio. In Revista Sinais Sociais, 1 (2),84-141.

UNESCO \& Ministério da Educação. (2009). Educação e aprendizagem para todos: olhares dos cinco continentes. Brasília: UNESCO \& Ministério da Educação do Brasil. Retirado de http://www.unesco.org/fileadmin/MULTIMEDIA/INSTITUTES/ UIL/confintea/pdf/Preparatory_Conferences/Conference_Documents/Latin America_-_Caribbean/confinteavi_olhares_5_continentes.pdf

UNESCO \& Ministério da Educação (2010). Marco de Ação de Belém. Brasília: UNESCO \& Ministério da Educação do Brasil. Retirado de http://www.unesco. org/fileadmin/MULTIMEDIA/INSTITUTES/UIL/confintea/pdf/working_documents/ Belem\%20Framework_Final_ptg.pdf 